5. Department of Health. Raising standards for patients, new partnerships in out-of-hours care: an independent review of GP out-of-hours services in England. London: Department of Health, 2000.

6. Stott NC, Davis RH. The exceptional potential in each primary care consultation. J R Coll Gen Pract 1979; 29(201): 201-205.

7. Thompson C, Hayhurst C, Boyle A. How have changes to out-of-hours primary care services since 2004 affected emergency department attendances at a UK District General Hospital? A longitudinal study. Emerg Med J 2010; 27(1): 22-25.

8. Care Quality Commission. Take Care Now. Newcastle upon Tyne: Care Quality Commission, 2010. http://www.cqc.org.uk/usingcareservices/healthcare/co ncernsabouthealthcare/takecarenow.cfm (accessed 10 Feb 2010).

9. Primary Care Foundation. Improving out of hours care what lessons can be learned from a national benchmark of services? East Sussex: Primary Care Foundation, 2010

http://www.primarycarefoundation.co.uk/page1/page 9/page19.html (accessed $10 \mathrm{Feb} 2010$ ).
10. Campbell J, Roland M, Richards S, et al. Users' reports and evaluations of out-of-hours health care and the UK national quality requirements: a cross-sectional study. Br J Gen Pract 2009; 59(558): e18-23.

11. Ungoed-Thomas J. Tories to make GPs give after-hours care. Times 2010; 17 Jan:

http://www.timesonline.co.uk/tol/news/politics/article6 991090.ece (accessed 16 Feb 2010).

12. House of Commons Official Report: Parliamentary Debates (HANSARD). 27 Jan 2010. 504 (31)

13. National Statistics. Living in Britain 2001: percentage living alone, by age: 1973 to 2001 .

http://www.statistics.gov.uk/lib2001/viewerChart4712.h tml (accessed 10 Feb 2010)

14. Salisbury C, Trivella M, Bruster S. Demand for and supply of out of hours care from general practitioners in England and Scotland: observational study based on routinely collected data. $B M J 2000 ; \mathbf{3 2 0}(7235)$ : 618-621.

15. Campbell SM, Reeves D, Kontopantelis E, et al. Effects of pay for performance on the quality of primary care in England. N Engl J Med 2009; 361(4): 368-378.
16. Colin-Thome D, Field S. General practice out-of-hours services. Project to consider and assess current arrangements. London, Department of Health and RCGP, 2010.

http://www.dh.gov.uk/dr_consum_dh/groups/dh_digit alassets/@dh/@en/@ps/documents/digitalasset/dh_1118 93.pdf (accessed 10 Feb 2010).

17. Berwick DM. A transatlantic review of the NHS at 60 . BMJ 2008; 337: a838.

DOI: 10.3399/bjgp10X483445

\section{ADDRESS FOR CORRESPONDENCE}

John L Campbell

Peninsula Medical School, Exeter, EX1

2LU. E-mail: john.campbel/@pms.ac.uk

\title{
Near-patient testing in primary care
}

In the current climate of streamlined health care with an emphasis on communitybased care and one stop clinics, the concept of near-patient testing is appealing. Near-patient testing (also known as point-of-care testing) is defined as an investigation taken at the time of the consultation with instant availability of results to make immediate and informed decisions about patient care, and has gained much attention over the last 15 years.

Near-patient testing offers a number of potential advantages in primary care, including earlier diagnosis, communication of diagnosis, and disease management, with potential for improved outcomes, improved patient satisfaction, and cost-effectiveness. Other potential advantages include reducing health inequalities by being accessible to certain hard to reach socioeconomic or ethnic groups. Use of simple urine testing strips and blood glucose measurements are routine in primary care, although more sophisticated near-patient tests have been limited to anticoagulant monitoring, diabetes management, and testing for Creactive protein and Helicobacter pylori.
A study in this issue of the BJGP by Laurence et al evaluated patient satisfaction in relation to near-patient testing in a large randomised controlled trial (RCT) in Australia. ${ }^{1}$ Four key results are highlighted in this study: patients felt that near-patient testing allowed discussion of the management of their condition with their GP; patients felt they were more motivated to look after their condition; patients preferred near-patient testing using finger prick tests; and they were more satisfied, in particular, those who had anticoagulant monitoring.

There have been only a few RCTs of patient satisfaction with near-patient testing and these have reported mixed findings. For example, one RCT showed that people with diabetes accepted nearpatients tests and confirmed that they may have potential benefits, such as saving time, reducing anxiety, and both patient management and job satisfaction. ${ }^{2,3}$ However, satisfaction with diabetes care was already high in both intervention and control groups and the trial failed to show any improvements in outcomes for these patients; in addition, there were no cost savings. $^{3}$ There is support among healthcare professionals for the principles of near-patient testing, ${ }^{3,4}$ although at the same time healthcare practitioners have concerns about time pressures, maintenance, quality control, and cost implications. ${ }^{4}$

In the UK there has been recent interest in lipid monitors which have increased in availability over the years with the potential to assess cardiovascular risk. $^{5}$ These machines have been validated for bias and imprecision and have been shown to have overall analytical goals for near-patient testing that are equivalent to those used in laboratories. ${ }^{5}$ One area where these monitors are being seriously considered in the UK is to help implementation of the ambitious NHS Health Check programme, ${ }^{6}$ in particular in the community pharmacy setting.

Previous studies have evaluated the feasibility of oral anticoagulant therapy monitoring using near-patient testing by community pharmacists, and have shown promising results. ${ }^{7}$ Furthermore, a recent evaluation of a cardiovascular risk screening programme by community pharmacists found that it was possible to provide near-patient cardiovascular 
disease risk assessment in deprived black and Asian communities, of whom $70 \%$ were referred for further tests to their GPs because of increased cardiovascular risk. ${ }^{8}$ Nevertheless, adequately powered rigorous evaluations are lacking.

If near-patient testing is to be implemented in primary care, then quality assurance of the programme will be a key recommendation. This will include quality control maintenance and external quality control. Guidelines also recommend quality assurance of near-patient testing to limit medical errors, and a mechanism for continued quality improvement. ${ }^{9}$ To help deliver the NHS Health Check programme, the recently published $A$ Practical Guide to Point of Care Testing is therefore timely. ${ }^{10}$ The guidance gives advice on quality assurance, the process for accreditation of healthcare professionals, and a buyers' guide to near-patient testing equipment. ${ }^{10}$

A systematic review of near-patient testing in primary care, published in 1999, concluded that there was little research evidence to guide expansion of the use of near-patient testing, and further research was recommended. ${ }^{11}$ Ten years on, there has been little progress in terms of rigorous evaluations of near-patient testing initiatives in primary care. A recent guideline summarised some of the evidence base for near-patient testing, especially in emergency departments, but the evidence base for its impact in improving outcomes in primary care was lacking, except for monitoring of people on anticoagulants and for management of people with type 2 diabetes. ${ }^{9}$ Near-patient testing has a number of potential benefits beyond patient satisfaction, although the full potential of its integration and implementation has not been exploited. Rigorous evaluations of translating this technology into primary care are still required to determine improvements in harder outcomes and cost-effectiveness.

\section{Kamlesh Khunti}

Professor of Primary Care Diabetes and Vascular Medicine, University of Leicester, Department of Health Sciences, Leicester.

\section{Provenance}

Commissioned; not peer reviewed.

\section{REFERENCES}

1. Laurence CO, Gialamas A, Bubner T, et al. Patient satisfaction with point-of-care testing in general practice. Br J Gen Pract 2010; 60(572): 10.3399/bjgp10X483508.

2. Khunti K, Stone MA, Burden AC, et al. Randomised controlled trial of near-patient testing for glycated haemoglobin in people with type 2 diabetes mellitus. Br J Gen Pract 2006; 56(528): 511-517.

3. Stone MA, Burden AC, Burden M, et al. Near patient testing for glycated haemoglobin in people with Type 2 diabetes mellitus managed in primary care: acceptability and satisfaction. Diabet Med 2007; 24(7): 792-795.

4. Butler CC, Simpson SH, Wood F. General practitioners perceptions of introducing near-patient testing for common infections into routine primary care: a qualitative study. Scand J Prim Health Care 2008; 26(1): $17-21$.

5. Rapi S, Bazzini C, Tozzetti C, et al. Point-of-care testing of cholesterol and triglycerides for epidemiologic studies: evaluation of the multicare-in system. Trans Res 2009; 153(2): 71-76.

6. Department of Health. Putting prevention first vascular checks: risk assessment and management. London: Department of Health, 2008.

7. Wilson SJ, MacLellan E, Cox JL, Meek W. A pilot study evaluating the feasibility of monitoring oral anticoagulant therapy with point-of-care testing in a community pharmacy. Can J Hosp Pharm 2004; 57(3): 158-164.

8. Horgan JM, Blenkinsopp A, McManus RJ. Evaluation of a cardiovascular disease opportunistic risk assessment pilot ('Heart MOT' service) in community pharmacies. J Public Health 2009; DOI: 10.1093/pubmed/fdp092.

9. Nichols JH, Christenson RH, Clarke W, et al. Executive summary. The National Academy of Clinical Biochemistry Laboratory Medicine Practice Guideline: evidence-based practice for point-of-care testing. Clin Chim Acta 2007; 379(1-2): 14-28.

10. NHS Improvement. Delivering the NHS Health Check: $a$ practical guide to implementation. A practical guide to point of care testing. Leicester: NHS Improvement, 2010.

11. Delaney BC, Hyde CJ, McManus RJ, et al. Systematic review of near patient test evaluations in primary care. BMJ 1999; 319(7213): 824-827.

DOI: 10.3399/bjgp10X483454

ADDRESS FOR CORRESPONDENCE

\section{Kamlesh Khunti}

University of Leicester, Department of Health Sciences, 22-28 Princess Road West, Leicester, LE1 6TP, UK

E-mail: kk22@le.ac.uk

\section{Tailoring treatment to risk in type 2 diabetes}

Detecting and managing type 2 diabetes forms an increasing part of everyday practice, with prevalence estimates suggesting that $3.5-5 \%$ of the UK population are affected. ${ }^{1}$ Although care has improved in recent years, partly because the Quality and Outcomes Framework (QOF) has encouraged systematic approaches to reducing metabolic risk, this success has prompted important questions about how aggressive therapy should be.

Managing hyperglycaemia is only part of diabetes care, but it seems to generate much of the controversy, with uncertainty about both the safety and affordability of new QOF targets ${ }^{2}$ and medications. ${ }^{3}$ On top of this, changes to the way that glycated hemoglobin $(\mathrm{HbA} 1 \mathrm{c})$ is reported will mean that clinicians need to spend time explaining the revised values to patients. ${ }^{4}$

In a sense, the paper from a Dutch group in this issue of the $B J G P^{5}$ confirms what we know from other observational studies: 